Полина Ермолаева, Ольга Бамева, Валерия Корунова

\title{
ЭКОЛОГИЧЕСКАЯ ПОЛИТИКА И ГРАЖДАНСКОЕ УЧАСТИЕ В РОССИЙСКИХ МЕГАПОЛИСАХ: ДОСТИЖЕНИЯ И ВЫЗОВЫ С ПОЗИЦИИ ГОРОДСКИХ СТЕЙКХОЛДЕРОВ
}

\begin{abstract}
В статье на материалах анализа документов, серии экспертных интервью с разными городскими стейкхолдерами $(\mathrm{N}=60)$, репрезентативного опроса населения городов Москвы и Казани $(\mathrm{N}=1500)$ раскрываются основные сложности и достижения экологической политики в крупных российских мегаполисах в мнениях различных городских групп. Внимание уделяется особенностям экологического гражданского участия и взаимодействия городских стейкхолдеров в экологической политике мегаполисов. Использование иммитационного подхода позволило проанализировать экологическую политику как серию симулякров: городские элиты симулируют вовлечение населения в городскую повестку, горожане- заинтересованность в такой деятельности. Анализ показал, что несмотря на усиление экологического компонента в стратегических целях развития российских городов, на практике проводимая политика обеспечивает лишь поверхностное улучшение экологической обстановки. Основная проблема в городах заключается в неоднозначности положений экологического законодательства, в неорганизованности межведомственного взаимодействия уполномоченных органов при принятии и реализации управленческих решений, а также в почти полном исключении из этого
\end{abstract}

Полина Олеговна Ермолаева- к. социол. н., доцент, кафедра общей и этнической социологии, Казанский федеральный университет, ст.н.с., Центр перспективных экономических исследований, Академия наук Республики Татарстан, Казань, Россия. Электронная почта: polina.ermolaeva@gmail.com

Ольга Александровна Башева- к. социол. н., н.с., Институт социологии, Федеральный научно-исследовательский социологический центр Российской академии наук, Москва, Россия. Электронная почта: olgaausacheva@yandex.ru

Валерия Олеговна Корунова- аспирант, н.с., отдел качественных исследований, Центр перспективных экономических исследований, Академия наук Республики Татарстан, Казань, Россия. Электронная почта: valeriya.korunova@tatar.ru 
процесса профессиональных экологов и представителей общественности. При этом мнения московских экспертов по вопросу их включения в принятие экологических решений разделились: одни считают, что экологи не участвуют в данном процессе, а другие, наоборот,- что все решения проходят их экспертную оценку. По мнению группы скептиков, их роль в экологической политике городов, а также весь процесс организации гражданского участия имеет символический перформативный характер и является срежиссированным политическими элитами. Симуляция гражданской вовлеченности в экологическую политику городов воспроизводит скептицизм, апатию и недоверие городских групп к публичной политике властей. На основе результатов исследования авторы приводят рекомендации по повышению эффективности экологической политики в городах и вовлечению различных групп населения в процесс принятия решений по социально-экологическим вопросам.

Ключевые слова: экологическая политика, гражданское экологическое участие, взаимодействие стейкхолдеров, симуляция, перформанс

DOI: 10.17323/727-0634-2021-19-2-301-314

Экологическая политика в России имеет долгую историю, отражающую меняющийся расклад экономических интересов и политических сил, при сохранении достаточно уязвимой позиции природоохранных отраслей в управлении (Халий, Левченко 2017: 65). Отсутствие четко очерченной федеральной экологической стратегии, неолиберальная логика развития городов, ослабление институтов защиты окружающей среды, несовершенство нормативного ландшафта в области природопользования являются ее ключевыми вызовами (Голубчиков, Махрова 2013; Henry 2010а). Среди исследователей экополитики и управления существует некоторый консенсус относительно понимания факторов ее эффективности. В частности, считается, что решение экологических проблем невозможно без целенаправленной политики государства, предусматривающей широкое вовлечение основных групп городских стейкхолдеров- гражданского общества, бизнеса, экспертного сообщества, природоохранных организаций (Ляховенко, Чулков 2017), а также формирования экологической культуры и экологического сознания населения (Халий, Левченко 2017; Халий 2015).

Гражданское участие определяется учеными как «любая деятельность, в которой субъекты реализуют свои гражданские права» (Diller 2001), «действия со стороны граждан, через которые происходит их участие, сотрудничество и усиление своей значимости» (Zlatareva 2008:3). При этом его осмысливают как интерактивный процесс, в соответствии с которым заботы, потребности и ценности гражданина включены в принятие государственных и корпоративных решений (Creighton 2005). Зигмунт Бауман (Bauman 2001) интерпретирует гражданское участие как необходимое горожанам для того, чтобы почувствовать свою принадлежность 
к группе, поскольку они все больше физически отдаляются друг от друга, теряют ощущение места и идентичности.

В России, согласно законодательству, гражданское участие является неотъемлемой частью реализации любых градостроительных проектов и реализуется в виде общественных слушаний, консультаций, консультирования и других форм участия. Исследование гражданского участия, экополитики и экоактивизма имеет более чем полувековую историю в российской общественной науке (Яницкий 2014; Yanitsky 2018). Одной из важных тем является исследование стратегий выживания и развития российских экологических некоммерческих организаций (Henry 2010b). Специфика низовых социальных инициатив в современной России-это их локальный характер и привязанность к конкретной и близкой людям проблеме (Клеман и др. 2010). В этой связи Борис Гладарев даже вводит в анализ такое понятие как «профессиональные горожане», воспринимающие «общее» городское пространство как «свое» и «чувствующие город» (Гладарев 2012). Подобные инициативы реализуются как в традиционных, очных формах, например, в виде протестов населения по поводу предпринимаемых властью решений локальной экологической проблемы (Маркин, Кинсбурский 2020), так и в новых, онлайн-формах - посредством формирования виртуальных объединений в пространстве социальных медиа (Гольбрайх 2019).

Наша статья направлена на дальнейшее теоретическое и эмпирическое насыщение поля отечественных исследований в области гражданского экологического участия. Мы предлагаем критический анализ экополитики и гражданского участия в крупных российских мегаполисах (на примере Москвы и Казани). Важно показать, во-первых, каким образом экологическая политика и гражданское экологическое участие проблематизируются в нормативных документах городов, мнениях экспертного сообщества и горожан. Во-вторых, какие достижения и сложности видят разные группы населения в реализации экологической политики и гражданского экологического участия в российских мегаполисах. В-третьих, сравнить города между собой по тому, как реализуется экологическая политика и гражданское участие. На основе полученных результатов будут сформулированы рекомендации по повышению эффективности экологической политики в городах и вовлечению различных групп населения в процесс принятия решений по социально-экологическим вопросам.

\section{Теоретические и методологические основания исследования}

В качестве теоретической рамки исследования нами выбран перформативный или имитационный подход (Бодрийяр 2007; Гофман 2003), согласно которому социальная реальность является видимостью и состоит из копий без оригиналов. Это возможно, поскольку человеческая деятельность нацелена 
на «управление впечатлениями», что превращает ее в представление этой деятельности. Как следствие, у реального нет возможности произвести себя, но оно заменяется «гиперреальным», где нет различия между реальным и воображаемым. Причем подобные имитации не обязательно являются намеренно сконструированными, скорее они могут быть результатом невежества и «близорукости» самих акторов репрезентаций (Ermolaeva, Lind 2020).

В случае экологической политики мы предполагаем несколько видов симулякров. Это симулякр вовлечения горожан в городскую политику со стороны элиты, который может быть воспроизведен через разные формы. Например, проведение общественных слушаний на конечных этапах реализации проекта, когда в действительности решение уже принято, привлечение только лидеров мнений или консультирование с определенными инклюзивными группами лоббистов. Применяя терминологию Эрвина Гофмана, можно сказать, что данные группы выступают в роли привратников, которые не позволяют широкой общественности включиться в реальные переговоры «в кулуарах», потому что если фасад и закулисье пересекутся, то это приведет к «испорченному действию» (Goffman 1967). В этом состоит перформативный характер такого вовлечения, при котором происходит иммитация включения общественности в городские изменения.

В качестве методологической базы нашего исследования использованы возможности сравнительного кейс-стади. Выбраны два кейса для анализароссийские мегаполисы Москва и Казань. Логика выбора этих городов заключается в их типологическом сходстве (крупнейшие урбанизированные ареалы России, центры инновационного развития страны) и различиях (географическое положение, структура и концентрация промышленности и занятости населения, уровень экологического загрязнения). Для обеспечения методологически корректных обобщений и сравнимости результатов использованы идентичные для городов инструментарии, методы сбора и обработки данных.

Нами выбрана комбинация качественной и количественной исследовательских стратегий с использованием следующих методов сбора социологической информации: анализ документов (опросов общественного мнения, федеральных и региональных программ), который проведен на начальных этапах исследования для изучения существующего дискурса в области экологической политики и для определения пула экспертов для интервью. На втором этапе проведены полуструктурированные экспертные интервью $(\mathrm{N}=60$, поровну в Казани и Москве) с представителями органов местного самоуправления, академическим сообеесвом, профессиональными группами экологов, архитекторами, урбанистами. На первом этапе анализа данных осуществлялся нарративный анализ, задача которого сводилась к тому, чтобы из прерывистого нелогичного рассказа сделать связный, упорядоченный текст. На втором этапе происходило уплотнение смыслов- сведение суждений информантов к коротким формулировкам, набору выводов. 
Количественная часть исследования выразилась в репрезентативном опросе (анкетирование) населения Москвы и Казани по стратифицированной случайной бесповторной выборке ( $\mathrm{N}=750$ для каждого города). Опрос проведен в 2018-2019 гг. Ошибка выборки составила 5\%. Анализ данных включал в себя дескриптивный анализ, двумерные распределения.

\section{Экологическая политика городов в пространствах нормативного дискурса и мнениях экспертов}

Согласно Проекту стратегии социально-экономического развития Москвы на период до 2025 г., экология выступает одним из множества условий жизни в городе, недостаточно высокое качество которой не позволяет реализовать конкурентные преимущества Москвы как мирового центра развития (Управа района Фили-Давыдково 2012). Стратегия социально-экономического развития города Казани до 2030 г. также включает экологию в число множества факторов, определяющих состояние городской среды. Ее высокое качество обеспечивает устойчивый экономический рост Казани и ее становление мировым городом (Решение Казанской городской Думы 2016). Таким образом, на уровне официального дискурса экологическая направленность развития в стратегических документах обоих городов просматривается, хоть и фрагментарно.

Несмотря на очевидную схожесть нормативных оснований осуществления экополитики, эффективность реализуемых в Москве и Казани мероприятий по официальным данным сильно различается. Так, в рейтинге экологического управления городов России Москва и Казань занимают второе и 18 места соответственно из 55 городов (РКС Тольятти 2015). В экологическом рейтинге российских городов 2017 г. ситуация изменяется в обратную сторону: Москва - на 16 месте, Казань - на втором месте среди 103 городов (Новости Тольятти 2017). По мнению экспертов, эффективность экополитики местных властей в обоих городах находится на низком уровне; конструктивные изменения экологической политики происходят, но скорее на формальном уровне, тогда как глубинные проблемы не решаются, порождая новые продукты имитационного процесса.

К основным достижениям экополитики Москвы эксперты относят: реализацию программ благоустройства и озеленения территорий, на которые тратятся большие финансовые средства, развитие корпоративной социальной и экологической ответственности, «зеленого» строительства, внедрение экологически устойчивого транспорта и практик экомобильности среди горожан, для реализации которых строятся дополнительные пешеходные зоны, велодорожки, заправки для электромобилей, развивается программа «каршеринга». Правда, эти практики и инфраструктуру для них еще предстоит серьезно масштабировать, поскольку, например, для такого крупного города как Москва, количество велодорожек незначительно и они концентрируются 
лишь в нескольких центральных районах. Последнее дает основания экспертам оценивать эти инициативы как «пиар-акции», не предусматривающие структурных изменений. Перечисленные симулякры творят гиперреальность устойчивых городов, что подрывает доверие горожан к реальности такого города для их ежедневных практик. В Казани круг основных достижений экополитики ограничивается решениями по вопросам озеленения и благоустройства территорий, в частности- развитием парков.

Препятствия реализации более основательного подхода к экополитике в городах эксперты называют разные. В Москве это- внутренняя неоднородность города, устаревшая инфраструктура и коммуникации, затрудняющие внедрение «зеленых» практик и технологий, отсутствие профильных экспертов во властных структурах, а также отсутствие наказаний за экологические правонарушения, создающее ощущение общей вседозволенности; в Казанинехватка целевого финансирования, а также отсутствие своевременности и оперативности в действиях местной власти, которая «пропускает» возникшие проблемы и допускает таким образом их обострение. Влияние приведенных сдерживающих факторов, однако, проявляется одинаково, и в качестве первой ключевой проблемы для обоих мегаполисов выступает отсутствие системности решений и «показной», перформативный характер экологических программ и инициатив. Данная проблема, по оценкам экспертов, фактически «обнуляет» все достижения.

Вторая ключевая проблема заключается в отсутствии межсекторного взаимодействия. Несмотря на то что часть экспертов высоко оценивает старания департаментов природопользования, несистемность программ и решений делают экополитику недостаточно эффективной, проигрывающей экономическим интересам города и его жителей. В Москве взаимодействие городских властей с предприятиями, НКО или научным сообществом очень сильно зависит от конкретного департамента. Например, департамент транспорта на текущий момент довольно активно сотрудничает с НКО по различным вопросам, с разными коммерческими организациями. Это сотрудничество оценивается экспертами как плодотворное. А вот департамент жилищно-коммунального хозяйства и благоустройства практически не взаимодействует ни с кем, как и департамент строительства. Экологи и общественность с трудом могут повлиять на управленческие решения, хотя формально каждый градостроительный проект сопровождается проведением общественных слушаний и экспертизы. Один из ученых высказался, что данная проблема существует не только на городском, но и на федеральном уровне.

Экополитика в городах имеет схожие нормативные основания и схожим образом оценивается экспертами. Ввиду отсутствия межсекторного взаимодействия при принятии экологических решений, а также их перформативности, сегодня можно говорить скорее об «имитации» городского природосохранения. 


\section{Форматы взаимодействия городских стейкхолдеров в экологической политике российских мегаполисов}

Открытость процесса принятия управленческих решений и возможность взаимодействия городской власти с НКО, экологами и общественностью выступает в качестве самостоятельной проблемы экополитики в городах. Эксперты приходят к выводу о недостатке подобных взаимодействий, в первую очередь- с НКО, являющимися активными игроками на поле экополитики, способными оказывать на нее конструктивное влияние, и тем самым подрывающих авторитет занятых в ней чиновников. Последние «привыкли принимать решения кулуарно и считают, что они знают лучше» (профессиональный эколог, Казань), что часто делает власть «закрытой», не готовой к совместному с общественными организациями решению экологических вопросов. При этом очевидна необходимость функционирования как можно большего количества НКО, «более специализированных и контактирующих между собой» (представитель академического сектора, Москва).

Мнения московских экспертов по поводу взаимодействия элит с профессиональными группами экологов разделились: одни считают, что экологи не участвуют в принятии управленческих решений, а другие, наоборот,- что все решения проходят их экспертную оценку. Аргументы первых сводятся к тому, что несмотря на наличие специально созданного общественного совета при Департаменте природопользования, его работа сводится к проведению научно-исследовательских работ, дальше обсуждения которых дела не идут. Вторые утверждают, что все строительные проекты сопровождаются экологической оценкой, документация проходит обязательную экспертизу. В Казани поддержку встречает первая точка зрения, характеризующая скорее символическую перформативную роль профессиональных экологов в управленческой повестке, которая является заведомо определенной политическими элитами, руководствующимися экономическими и социальными приоритетами. Экологические приоритеты при разработке казанских стратегий, программ и проектов учитываются в последнюю очередь или не учитываются вовсе, оценки экологов зачастую оказываются спрограммированы с целью обоснования принятых управленческих решений, а их влияние на состояние окружающей среды обсуждается уже постфактум. В общественные слушания вовлекаются группы лоббистов, которые выступают в данном перформансе в качестве привратников для широкой общественности, сдерживая их от «испорченного действия». Значительный перевес в политическом, экономическом и социальном капиталах у ресурсных групп вызывает апатию среди профессиональных экологов относительно участия в решении социально-экологических вопросов.

Особую остроту приобретает проблема гражданского участия в решении экологических вопросов. Эксперты оценивают возможности такого участия как «ниже среднего» в обоих городах в связи с нежеланием органов власти 
прислушиваться к мнению горожан и сотрудничать с ними: «Они же только запросы пинают из стороны в сторону, не найдя, как говорится... ответственных лии, присылают тебе обратно» (представитель активистского сектора, Казань). Эксперты из обоих городов называют общественные слушания малоэффективным инструментом воздействия. Информация об их проведении и состоянии дел часто замалчивается от населения, а в ходе слушаний стороны «практически друг друга не сльишат» и «решение, удовлетворяющее всех, не находят». Перечисленные симулякры творят гиперреальность вовлечения населения в решение городских экологических проблем, что, в свою очередь, обесценивает такое участие. Так, большинство горожан считают, что в целом местные органы власти неактивно привлекают население к решению вопросов, связанных с экологией (60\% в Москве и 56,1\% в Казани). Причем с течением времени ситуация практически не меняется. Половина москвичей и казанцев (50,8\% и 53,3\% соответственно) считает, что возможностей влиять на действия городских властей и предприятий по экологическим вопросам у них за последние пять лет не стало ни больше, ни меньше. Не изменилось, по мнению населения, и внимание властей к экологическим вопросам (49,8\% - в Москве, 50,1\% - в Казани), его сегодня характеризуют как «среднее». Также скорее не изменился уровень открытости и доступности информации по разным экологическим показателям для заинтересованных лиц (54,4\% - в Москве, 50,4\% - в Казани), горожане его тоже оценивают как «средний», а эксперты-как «ниже среднего».

Слабое вовлечение населения в городскую экоповестку, ощущение имитации диалога между его акторами является причиной низкой гражданской активности в вопросах сохранения окружающей среды. Согласно опросу, в общественных слушаниях и обсуждениях участвовали $10,8 \%$ москвичей и $8,8 \%$ казанцев, когда-либо организовывали социальные обсуждения по экологическим вопросам только 2,3\% москвичей и 2,9\% казанцев. Самостоятельно писали письма в соответствующие инстанции 9,2\% москвичей и $8 \%$ казанцев. Эти данные соотносятся с общероссийскими, полученными ВЦИОМ, согласно которым, 61 \% населения считает, что не может самостоятельно повлиять на экологию в месте своего проживания (ВЦИОМ 2018).

Здесь можно отметить двойную имитацию: с одной стороны, симулируется вовлечение населения в принятие городских экологических решений (в реальности-решения определены городской элитой заранее), с другойнаселением имитируется недовольство слабого вовлечения в гражданскую активность (в действительности- каждый занят своими повседневными проблемами, нежели общественным устройством). В подтверждение последнего тезиса любопытны данные опроса, которые свидетельствуют о низкой информированности и обеспокоенности населения экологическими проблемами, особенно, по мнению экспертов, не касающимися их напрямую: «Очень мало жителей поддерживает, то есть очень трудно расшевелить жителей района самих, донести до них, что это важно, что 
им самим тут надо» (представитель бизнеса, Москва). Прямое столкновение с экологическими проблемами, например, в районе непосредственного проживания, как правило, повышает вовлеченность населения в процесс принятия управленческих решений.

\section{Заключение}

В статье на основе анализа документов, экспертных интервью и опроса проанализированы особенности реализации экологической политики и гражданского участия в крупных российских мегаполисах (на примере Москвы и Казани). В качестве теоретической рамки анализа выбран имитационный подход, согласно которому происходит подмена реальных явлений воображаемыми. На этом основании возникают разного рода симулякры, которые выступают продуктами имитационного процесса. В частности, нами описаны симулякры вовлечения населения в экологическую политику городскими элитами (в реальности- элиты воспроизводят практики, которые не предусматривают публичного диалога с населением) и городского экоучастия и активности населения (на практике-люди заняты повседневными проблемами, нежели общественным устройством).

В целом можно наблюдать положительные тенденции в экополитике за счет развития масштабных городских программ озеленения, благоустройства, внедрения экологических инноваций; экологическая повестка приобрела гласность, проводятся различные мероприятия, появляются площадки, на которых стейкхолдеры могут дискутировать; растет и заинтересованное экосообщество. В Казани к основным достижениям экологической политики эксперты отнесли общее озеленение города, в то время как в Москве-развитие «зеленого» строительства, внедрение экологически устойчивого транспорта и практик экомобильности среди горожан. Несмотря на усиление экологического компонента в стратегических целях развития российских городов, на практике проводимая политика не обеспечивает глубинных системных преобразований.

Ключевой проблемой в обоих городах является неорганизованность межведомственного взаимодействия уполномоченных органов при принятии и реализации управленческих решений, а также почти полная исключенность из этого процесса профессиональных экологов, НКО и населения. При этом мнения московских экспертов по вопросу их включения в принятие экологических решений разделились поровну: одни считают, что экологи не участвуют в данном процессе, а другие, наоборот,- что все решения проходят их экспертную оценку; в то время как в Казани больше поддержки встречает первая группа скептиков. Основными барьерами на пути гражданской инклюзии в экологическую повестку Москвы являются внутренняя неоднородность города, устаревшая инфраструктура и коммуникации, в Казанив первую очередь они связаны с дефицитом целевого финансирования. 
По мнению большинства городских групп, их роль в экополитике, а также весь процесс организации гражданского участия имеет символический перформативный характер и является заведомо определенным политическими элитами. Симуляция гражданской вовлеченности в экологическую политику со стороны политических элит воспроизводит недоверие, скептицизм и апатию среди городских групп к публичной политике властей. Это усугубляется такими экстернальными барьерами, как излишняя забюрократизированность общественных слушаний, постоянно меняющийся нормативный ландшафт общественного участия, низкий уровень информированности населения, а также следующими внутренними барьерами: недостаток экологической экспертизы и знаний среди широкого круга общественности, дефицит временного ресурса и экономического капитала для легитимации своих требований. В конечном счете формируется инертность населения в экологических вопросах (Sheedy et al. 2008), что коррелирует с данными похожих исследований (Ermolaeva 2014; Crotty 2012), которые демонстрируют низкий уровень доверия к властным элитам и патерналистические ценности среди населения или «социальный индивидуализм»перекладывание ответственности за принятие экологических решений на государство. Население вовлекается в экологическую политику (и в целом в решение экологических проблем) только в экстренных случаях, когда вопрос экологической безопасности касается лично (их двора, дома, парка).

Среди рекомендаций, которые предложили сами стейкхолдеры для усиления своей роли в экологической политике городов и налаживания эффективных взаимодействий с городскими элитами, можно выделить следующие: (1) учитывать мнение населения на начальной стадии проектирования объектов, так как проведение публичных консультаций до строительства объектов способно сгладить социальные напряженности, а развитие системы публичных консультаций, обсуждений позволит максимизировать социальную и экономическую включенность населения; (2) трансформировать общественные слушания из информационного мероприятия в дискуссионное, проводимое на единой (электронной) площадке с целью повышения открытости власти к беспокойству и предложениям со стороны всех заинтересованных лиц, особенно со стороны профессиональных экологов и местного населения; (3) усилить вовлечение граждан в экологическую повестку городов через повышение их уровня просвещения и экологического образования.

\section{Материалы для анализа}

ВЦИОМ (2018) Экологическая ситуаџия в России: мониторинг. Доступно по ссылке: https://wciom.ru/index.php?id=236\&uid=9267 (дата обращения: 10 августа 2020).

Новости Тольятти (2017) Экологический рейтинг российских городов 2017: Список. Доступно по ссылке: https://augustnews.ru/ekologicheskij-rejting-rossijskih-gorodov-2017spisok/ (дата обращения: 13 февраля 2021).

Решение Казанской городской Думы (2016) О Стратегии социально-экономического развития мунищипального образования г. Казани до 2030 года № 2-12 от 14.12.2016 г.

РКС Тольятти (2015) Рейтинг экологического управления городов России - 2015. Доступно по ссылке: http://volcomsys.ru/userfiles/files/rejting.pdf (дата обращения: 13 февраля 2021). 
Управа района Фили-Давыдково (2012) Проект «Стратегии сочиально-экономического развития города Москвы на период до 2025 года». Доступно по ссылке: https://fili-davydkovo. mos.ru/important-information/the-project-strategy-of-socio-economic-development-of-the-cityof-moscow-for-the-period-till-2025.php (дата обращения: 10 августа 2020).

\section{Список источников}

Бодрийяр Ж. (2007) К критике политической экономии знака. М.: Академический проект. Гладарев Б. (2012) Градозащитные движения Петербурга накануне «зимней революции» 2011-2012 гг.: анализ из перспективы французской прагматической социологии. Мониторинг общественного мнения, 4 (110):29-43.

Голубчиков О., Махрова А. (2013) Факторы неравномерного развития российских городов. Вестник Московского университета. Серия 5: География, (2):54-60.

Гольбрайх В. (2019) Социальные медиа в локальных экологических конфликтах. Вестник Санкт-Петербургского университета. Соичилогия, 4 (12):368-384.

Гофман И. (2003) Анализ фреймов: эссе об организации повседневного опыта. М.: Институт социологии РАН.

Клеман К., Мирясова О., Демидов А. (2010) От обывателей к активистам. Зарождающиеся соииальные движения в современной России. М.: Три квадрата.

Ляховенко О., Чулков Д. (2017) Основные экологические проблемы российских городов и стратегия их разрешения. Российская политология, (3): 21-26.

Маркин В., Кинсбурский А. (2020) Сложносоставной региональный конфликт (на примере ситуации вокруг горы Тратау в Республике Башкортостан). Сочиологическая наука и соииальная практика, 2 (30): 101-113.

Халий И. (2015) Экологическое сознание населения современной России. История и современность, 1 (21): 189-205.

Халий И., Левченко Н. (2017) Экологическое сознание населения России. О. В. Аксенова (ред.) Асимметрия жизни современного российского общества: соотношение традиций и инноваиий. М.: ФНИСЦ РАН: 60-83.

Яницкий О. (2014) Экологический архив О. Н. Яницкого. М.: ФНИСЦ РАН.

Bauman Z. (2001) Community: Seeking Safety in an Insecure World. Cambridge: Polity Press. Creighton J. (2005) The Public Participation Handbook: Making Better Decisions Through Citizen Involvement. San Francisco: Jossey-Bass.

Crotty R. (2012) The Impact of Building Information Modelling. London: Routledge.

Diller E. (2001) Citizens in Service: The Challenge of Delivering Civic Engagement Training to National Service Programs. Washington, DC: Corporation for National and Community Service. Ermolaeva P. (2014) Citizen (Dis)Engagement during Assessment of Sports Mega-Events: The Case of the 2013 Universiade in Kazan, Russia. Impact Assessment and Project Appraisal, 32 (1):66-71. Ermolaeva P., Lind A. (2020) Mega-Event Simulacrum: Critical Reflections on the Sustainability Legacies of the World Cup 2018 for the Russian Host Cities. Problems of Post-Communism. Available at: https://doi.org/10.1080/10758216.2020.1791185.

Goffman E. (1967) Interaction Ritual: Essays on Face-to-Face Behavior. Chicago, IL: Anchor Books.

Henry L. (2010a) Between Transnationalism and State Power: The Development of Russia's Post-Soviet Environmental Movement. Environmental Politics, 19 (5): 756-781.

Henry L. (2010b) Red to Green. Environmental Activism in Post-Soviet Russia. New York: Cornell University Press.

Sheedy A., MacKinnon M., Pitre S., Watling J., Networks C. (2008) Handbook on Citizen Engagement: Beyond Consultation. Available at: https://atrium.lib.uoguelph.ca/xmlui/bitstream/ handle/10214/3133/Sheedy_Handbook_on_Citizen_Engagement-_Beyond_Consultation_ complete.pdf; sequence $=26$ (accessed 10 August 2020).

Yanitsky O. (2018) The Development of the Russian Environmental Movement in the beginning of XXI Century. International Journal of Humanities Social Sciences and Education, 5 (6): 23-31.

Zlatareva M. (2008) Promoting Civic Engagement in a Post-Totalitarian and EU Accession Context: A Case from Bulgaria. New York: UNDP. 
Polina Ermolaeva, Olga Basheva, Valeria Korunova

\title{
ENVIRONMENTAL POLICY AND CIVIC PARTICIPATION IN RUSSIAN MEGACITIES: ACHIEVEMENTS AND CHALLENGES FROM THE PERSPECTIVE OF URBAN STAKEHOLDERS
}

\begin{abstract}
Based on the analysis of documents, a series of expert interviews with different city stakeholders $(n=60)$, and a representative survey of the population of the cities of Moscow and Kazan $(n=1500)$, the authors provide insights on the main difficulties and achievements of environmental policy in large Russian megacities. The use of imitation approach permitted an analysis of environmental policy in two cities as a series of simulacrums: urban elites simulate the involvement of the population in the urban agenda, citizens simulate interest in such activities. Despite the strengthening of the environmental component in the strategic development goals of the Russian cities, in practice, the policy pursued provides only an imitational improvement of the environmental situation. The main problem in both cities is the ambiguity of environmental legislation provisions, the disorganized interdepartmental interaction of authorized bodies in making and implementing managerial decisions, as well as the almost complete exclusion of professional ecologists and members of the public from this process. The opinions of Moscow experts on their inclusion in environmental decisions are divided: some believe that environmentalists are not involved in this process, and others that all decisions are peer-reviewed; while in Kazan, the first group of sceptics meets more support. According to the group of sceptics, their role in the environmental policy of cities, as well as the entire process of organizing civic participation, is of a symbolic performative nature, and is deliberately orchestrated by political elites. The authors make recommendations for improving the effectiveness of environmental policy in cities and involving various groups of the population in the decision-making process on social and environmental issues.
\end{abstract}

Keywords: environmental policy, environmental civic engagement, stakeholder interaction, simulation, performance

DOI: 10.17323/727-0634-2021-19-2-301-314

Polina Ermolaeva - Cand. Sci. (Sociol.), Associate Professor, Department of General and Ethnic Sociology, Kazan Federal University, Senior Researcher, Center of Advanced Economic Research in the Academy of Sciences of the Republic of Tatarstan, Kazan, Russian Federation. Email: polina.ermolaeva@gmail.com

Olga Basheva- Cand. Sci. (Sociol.), Researcher of the Institute of Sociology, Federal Center of Theoretical and Applied Sociology of the Russian Academy of Sciences, Moscow, Russian Federation. Email: olgaausacheva@yandex.ru

Valeria Korunova- Graduate Student, Researcher of Department of Qualitative Research, Center of Advanced Economic Research in the Academy of Sciences of the Republic of Tatarstan, Kazan, Russian Federation. Email: valeriya.korunova@tatar.ru 


\section{References}

Baudrillard J. (2007) K kritike politicheskoy ekonomii znaka [On Criticism of the Political Economy of the Sign]. Moscow: Akademicheskiy proekt.

Bauman Z. (2001) Community: Seeking Safety in an Insecure World. Cambridge: Polity Press.

Clement K., Miryasova O., Demidov A. (2010) Ot obyvateley k aktivistam. Zarozhdayushchiesya sotsial'nye dvizheniya v sovremennoy Rossii [From Ordinary People to Activists. Emerging Social Movements in Modern Russia]. Moscow: Tri kvadrata.

Creighton J. (2005) The Public Participation Handbook: Making Better Decisions Through Citizen Involvement. San Francisco: Jossey-Bass.

Crotty R. (2012) The Impact of Building Information Modelling. London: Routledge.

Diller E. (2001) Citizens in Service: The Challenge of Delivering Civic Engagement Training to National Service Programs. Washington, DC: Corporation for National and Community Service.

Ermolaeva P. (2014) Citizen (Dis)Engagement during Assessment of Sports Mega-Events: The Case of the 2013 Universiade in Kazan, Russia. Impact Assessment and Project Appraisal, 32 (1):66-71.

Ermolaeva P., Lind A. (2020) Mega-Event Simulacrum: Critical Reflections on the Sustainability Legacies of the World Cup 2018 for the Russian Host Cities. Problems of Post-Communism. Available at: https://doi.org/10.1080/10758216.2020.1791185.

Gladarev B. (2012) Gradozashchitnye dvizheniya Peterburga nakanune 'zimney revolyutsii' 20112012 gg.: analiz iz perspektivy frantsuzskoy pragmaticheskoy sotsiologii [Urban Protection Movements of St. Petersburg on the Eve of the 'Winter Revolution' 2011-2012: Analysis from the Perspective of French Pragmatic Sociology]. Monitoring obshchestvennogo mneniya [Monitoring of Public Opinion], 4 (110):29-43.

Goffman E. (2003) Analiz freymov: esse ob organizatsii povsednevnogo opyta [Frame Analysis: Essay on the Organization of Everyday Experience]. Moscow: Institut sotsiologii RAN.

Goffman E. (1967) Interaction Ritual: Essays on Face-to-Face Behavior. Chicago, IL: Anchor Books.

Gol'brajh V. (2019) Cocial'nye media v lokal'nyh jekologicheskih konfliktah [Social Media in Local Environmental Conflicts]. Vestnik of Saint-Petersburg University. Sociology, 4 (12):368-384.

Golubchikov O., Makhrova A. (2013) Faktory neravnomernogo razvitiya rossiyskikh gorodov [Factors of Uneven Development in Russian Cities]. Vestnik Moskovskogo universiteta. Seriya 5: Geografiya [Moscow University Bulletin. Series 5, Geography], (2): 54-60.

Henry L. (2010a) Between Transnationalism and State Power: The Development of Russia's Post-Soviet Environmental Movement. Environmental Politics, 19 (5): 756-781.

Henry L. (2010b) Red to Green. Environmental Activism in Post-Soviet Russia. New York: Cornell University Press.

Khaliy I., Levchenko N. (2017) Ekologicheskoe soznanie naseleniya Rossii [Ecological Consciousness of the Population of Russia]. In: O.V. Aksenova (ed.) Asimmetriya zhizni sovremennogo rossiyskogo obshchestva: sootnoshenie traditsiy i innovatsiy [Asymmetry of the Life of Modern Russian Society: The Ratio of Traditions and Innovations]. Moscow: FNISTs RAN:60-83.

Khaliy I. (2015) Ekologicheskoe soznanie naseleniya sovremennoy Rossii [Ecological Consciousness of the Population of Modern Russia]. Istoriya i sovremennost' [History and Modernity], 1 (21): 189-205. 
Lyakhovenko O., Chulkov D. (2017) Osnovnye ekologicheskie problemy rossiyskikh gorodov i strategiya ikh razresheniya [The Main Environmental Problems of Russian Cities and the Strategy for Their Resolution]. Rossiyskaya politologiya [Russian Political Science], (3):21-26.

Markin V., Kinsburskij A. (2020) Slozhnosostavnoj regional'nyj konflikt (na primere situacii vokrug gory Tratau v Respublike Bashkortostan) [Complex Regional Conflict (On the Example of the Situation around Mount Toratau in the Republic of Bashkortostan)]. Sociologicheskaja nauka i social'naja praktika [Sociological Science and Social Practice], 2 (30): 101-113.

Sheedy A., MacKinnon M., Pitre S., Watling J., Networks C. (2008) Handbook on Citizen Engagement: Beyond Consultation. Available at: https://atrium.lib.uoguelph.ca/xmlui/bitstream/ handle/10214/3133/Sheedy_Handbook_on_Citizen_Engagement-_Beyond_Consultation_ complete.pdf; sequence $=26$ (accessed 10 August $202 \overline{0})$.

Yanitsky O. (2018) The Development of the Russian Environmental Movement in the beginning of XXI Century. International Journal of Humanities Social Sciences and Education, 5 (6):23-31.

Yanitskiy O. (2014) Ekologicheskiy arkhiv O. N. Yanitskogo [Environmental Archive of O. N. Yanitsky]. Moscow: FNISTs RAN.

Zlatareva M. (2008) Promoting Civic Engagement in a Post-Totalitarian and EU Accession Context: A Case from Bulgaria. New York: UNDP. 